\title{
Verification and application of the extended spectral deconvolution algorithm (SDA+) methodology to estimate aerosol fine and coarse mode extinction coefficients in the marine boundary layer
}

\author{
K. C. Kaku ${ }^{1}$, J. S. Reid ${ }^{2}$, N. T. O'Neill ${ }^{3}$, P. K. Quinn ${ }^{4}$, D. J. Coffman ${ }^{4}$, and T. F. Eck ${ }^{5,6}$ \\ ${ }^{1} \mathrm{CSC}$, Monterey, CA, USA \\ ${ }^{2}$ Naval Research Laboratory, Monterey, CA, USA \\ ${ }^{3}$ Universitè de Sherbrooke, Sherbrooke, Québec, Canada \\ ${ }^{4}$ Pacific Marine Environmental Laboratory, NOAA, Seattle, WA, USA \\ ${ }^{5}$ Universities Space Research Association, Columbia, MD, USA \\ ${ }^{6}$ NASA Goddard Space Flight Center, Greenbelt, MD, USA \\ Correspondence to: K. C. Kaku (kkaku@csc.com)
}

Received: 8 January 2014 - Published in Atmos. Meas. Tech. Discuss.: 13 March 2014

Revised: 18 August 2014 - Accepted: 31 August 2014 - Published: 8 October 2014

\begin{abstract}
The spectral deconvolution algorithm (SDA) and SDA+ (extended SDA) methodologies can be employed to separate the fine and coarse mode extinction coefficients from measured total aerosol extinction coefficients, but their common use is currently limited to AERONET (AErosol RObotic NETwork) aerosol optical depth (AOD). Here we provide the verification of the SDA+ methodology on a nonAERONET aerosol product, by applying it to fine and coarse mode nephelometer and particle soot absorption photometer (PSAP) data sets collected in the marine boundary layer. Using data sets collected on research vessels by NOAAPMEL(National Oceanic and Atmospheric Administration Pacific Marine Environmental Laboratory), we demonstrate that with accurate input, SDA+ is able to predict the fine and coarse mode scattering and extinction coefficient partition in global data sets representing a range of aerosol regimes. However, in low-extinction regimes commonly found in the clean marine boundary layer, SDA+ output accuracy is sensitive to instrumental calibration errors. This work was extended to the calculation of coarse and fine mode scattering coefficients with similar success. This effort not only verifies the application of the SDA+ method to in situ data, but by inference verifies the method as a whole for a host of applications, including AERONET. Study results open the door to much more extensive use of nephelometers and PSAPs, with the ability to calculate fine and coarse mode scattering and extinction coefficients in field campaigns that do not have the resources to explicitly measure these values.
\end{abstract}

\section{Introduction}

One vital degree of freedom in aerosol optical characteristics is the partition between fine and coarse mode aerosol particles. While smaller Aiken/nucleation and larger giant modes contain significant aerosol particle number and mass, respectively, nucleation particles do not have significant surface area cross sections and giant particles have short residence times in the atmosphere. Thus, such particles only account for a second-order contribution to the radiative budget. In their simplest form aerosol models have a bi-modal aerosol distribution with optically active fine (approximate diameter range: $0.1-1 \mu \mathrm{m}$ ) and coarse (approximate diameter range: $1-15 \mu \mathrm{m})$ particle sizes. These modes are often treated as independent, externally mixed particle size distributions which can extend into each other's diameter space. While not fully physical (internal mixing of pollution on dust and the presence of more than two optically active modes are two possible perturbations), external mixing is an adequate assumption and an essentially robust scenario within the models, except perhaps in the most polluted or hazy environments (Eck et al., 2010, 2012). Fine mode particles, typically with a volume median diameter (VMD) between 0.2 and $0.5 \mu \mathrm{m}$, are largely produced by combustion including open biomass burning, biofuel use, and industrial pollution. Coarse mode particles, with VMDs on the order of 3-10 $\mu \mathrm{m}$, are principally mechanically generated and include dust and sea salt. Hence, knowing the partition between fine and coarse modes 
within total aerosol extinction is important for estimating the anthropogenic aerosol burden and calculating the direct climate forcing caused by anthropogenic aerosols (e.g., Chin et al., 2004; Bates et al., 2006), as well as estimating the presence of smoke and volcanic sulfates (e.g., Ansmann et al., 2011). Furthermore, fine and coarse mode particles have distinct spectral behaviors. Coarse mode particles are generally spectrally flat at larger solar wavelengths, while fine mode particles rapidly fall off in extinction with increasing wavelengths (e.g., Eck et al., 1999). Thus if the fine/coarse extinction and scattering partition can be constrained, much of their spectral behavior can be described (O'Neill et al., 2008).

Characterizing the bi-modal nature of optically active particles is an important design point of nearly all atmospheric aerosol field programs. Often, an impactor or other size selection device with a diameter size cut of $1 \mu \mathrm{m}$ is used upstream of a nephelometer so that the fine mode scattering can be isolated. A simultaneous measurement of total scattering is sometimes also made, and the difference of fine from total yields coarse mode components. From these measurements, submicron fraction (SMF: submicron extinction coefficient divided by total extinction coefficient) can be calculated. While straightforward, there are difficulties with this method. First and foremost is that the minimum between fine and coarse mode volume distributions, while dependent on relative humidity $(\mathrm{RH})$, is rarely $1 \mu \mathrm{m}$ but typically closer to $0.8 \mu \mathrm{m}$ (e.g., Fitzgerald, 1991; Rissler et al., 2006) and part of the coarse mode often encroaches on the fine mode measurement (E. A. Reid et al., 2003; J. S. Reid, 2003, 2006) and vice versa (Eck et al., 2010, 2012). In marine or dusty conditions this can lead to substantial fine mode scattering coefficient measurement errors. The effect is clearly exacerbated by increasing cut diameters: the fine mode signature can be fully swamped by the coarse mode signature if a $2.5 \mu \mathrm{m}$ size cut is used as is often done in association with air quality studies (e.g., Atwood et al., 2013). A second issue is that the difference method requires two nephelometers if simultaneous measurements are desired. To determine fine and coarse mode aerosol extinction coefficients, it is necessary to add two particle soot absorption photometers (PSAPs; Bond et al., 1999) or similar instrumentation to measure particle absorption coefficients. If particle hygroscopicity is to be studied with dry and humidified scattering coefficients measured, then at least four nephelometers are required for contiguous data of both fine and coarse mode scattering coefficients. This suite of instruments is unsupportable in smaller field campaigns and has rarely been achieved in historical data sets. Methodologies to retrospectively calculate fine and coarse mode scattering and extinction coefficients extend the usefulness of many data sets and provide greater global and historical knowledge of fine and coarse mode aerosol optical properties.

Within the realm of spectral sun photometer data, the fine/coarse partition and fine mode fraction (FMF: fine mode extinction divided by total extinction) are frequently generated products. Note that FMF is different from the SMF in that FMF does not use an artificially generated cut point; the partition is determined optically from the distinctive spectral properties of fine and coarse mode particles. Using almucantar sky radiance data, the Dubovik and King (2000) retrievals of aerosol particle size and optical properties from the AERONET (AErosol RObotic NETwork) sun photometer network are a mainstay of global aerosol science. However, such inversions are limited to sun photometers sites with sky scanning capability and to the necessarily coarse temporal resolution associated with sky scanning measurements compared to extinction measurements (nominal sampling intervals of an hour (when solar zenith angle exceeds 45 degrees) and $3 \mathrm{~min}$ for the latest generation of AERONET instruments).

Shortly after the Dubovik and King (2000) paper, O'Neill et al. (2001a, 2003) developed the spectral deconvolution algorithm (SDA) methodology using only aerosol optical depth (AOD) spectra to separate fine and coarse mode contributions to atmospheric AOD at a reference wavelength (typically taken at $500 \mathrm{~nm}$ ). More recently O'Neill et al. (2008) developed SDA+, which extends the calculated reference wavelength fine and coarse mode AODs of the SDA to fine and coarse mode AOD spectra that are coherent with the asymptotic constraints of the fine mode and the analytical constraints of a bi-modal size distribution. One advantage of the SDA and SDA+ is that the separation into fine and coarse mode AOD is entirely based on the spectral properties of the AOD: no assumed diameter minimum between modes is necessary. The SDA has been applied to AERONET measurements, and has compared well to simultaneously derived Dubovik and King (2000) inversions of fine-coarse AOD partitions (O'Neill et al., 2003, 2012; Eck et al., 2010). The SDA and SDA+ have been used to extract fine and coarse mode AOD parameters measured by sun photometers in many locations with the results in agreement with direct aerosol measurements (e.g., measured aerosol size distributions) and the Dubovik and King (2000) inversions, including regimes dominated by coarse mode dust, fine mode pollution, Arctic, biomass burning, and marine aerosols (e.g., O'Neill et al., 2008; Eck et al., 2010; Salinas et al., 2013). The SDA has been used to correct for thin cirrus contamination in AERONET data (Chen et al., 2012). Its optical coherence with lidar measurements of backscatter coefficient and depolarization ratio profiles has been illustrated for various types of aerosol events (Saha et al., 2010, O'Neill et al., 2012; Cottle et al., 2013). The SDA methodology has also been successfully applied to extinction coefficient measurements acquired in the Gulf of Mexico by cavity ring down (CRD) instruments (Atkinson et al., 2010).

In this paper we present a first-time comprehensive extinction coefficient analysis from SDA+ results across diverse environments. We will demonstrate how the SDA+ algorithm can be applied to in situ field data collected by a TSI 3-wavelength $(\lambda)$ nephelometer (Anderson and Ogren, 
1995) and PSAP, commonly deployed light scattering and absorption measurement instruments. If an SDA+ retrieval applied to such low-order extinction spectra is successful, an important complementary parameter can be added to the output retrievals of the nephelometer and PSAP. Because there is significant curvature in the scattering coefficient spectrum, and because the contribution of the typically weak-amplitude aerosol absorption coefficient to the curvature is small, the $\mathrm{SDA}+$ method may be further employed to compute fine and coarse mode scattering coefficients.

Unlike total spectral AOD or CRD extinction coefficient measurements, however, application of the SDA+ method to nephelometer and PSAP data sets is susceptible to additional complicating constraints. First, the spectral range of the $3-\lambda$ nephelometer and PSAP data is much shorter than sun photometers whose spectra extent nominally spans from the UV to the near IR (approximately the same range for many CRDs). Thus there is inherently less signal range to construct the first and second-order spectral derivatives that are employed here for the SDA+ retrievals. Second, at three wavelengths (i.e., the minimum to calculate a second derivative), individual calibration error in any one band can introduce significant spectral error. The redundancy of the five bands employed in AERONET retrievals reduces the impact of any single band that suffers from such calibration errors. Finally, nephelometer and absorption instruments need statedependent corrections for particle size dependent truncation and the non-Lambertian light source (Anderson and Ogren, 1995).

In this paper we examine the applicability of the SDA+ algorithm to nephelometer and PSAP data collected by the NOAA Pacific Marine Environmental Laboratory Atmospheric Chemistry Research Group (PMEL: downloaded from http://saga.pmel.noaa.gov/data/) in eight field campaigns performed between 1997 and 2008 across three oceans, two hemispheres, and in environments ranging from heavily polluted to relatively clean marine air and from tropical to Arctic (e.g., Quinn and Bates, 2005). In these projects, both fine and sub-10 $\mu \mathrm{m}$ aerosol data were collected. Examining varied data and aerosol species, we compare SDA+generated fine mode scattering and extinction coefficients derived from measured sub- $10 \mu \mathrm{m}$ scattering and extinction coefficient spectra to those measured using an instrumentally defined, inter-modal cut point. We scrutinize instrument calibration and perform data analyses to infer the importance of precise inputs to the SDA+ algorithm, particularly in lowextinction regimes. We close with an assessment of the suitability of the SDA+ algorithm for in situ use and with discussions of method strengths and shortcomings.

\section{Theoretical basis of the Ångström exponent, SDA and SDA+}

One of the most common methods for semi-quantitatively estimating the FMF extinction is the use of the classical Angström exponent (sometimes referred to as the Ångström coefficient). For clarity, we will refer to the classical Ångström exponent using å as opposed to the spectral derivative Ångström exponent $(\alpha)$ defined later in this section. Equation (1) defines the original spectral dependence of extinction as derived by Ångström (1929):

$\sigma_{\mathrm{ep}}=\sigma_{\mathrm{ep}, 1} \cdot \lambda^{-\mathrm{a}}$,

where $\sigma_{\mathrm{ep}}$ is the particle extinction at a particular wavelength $(\lambda)$, and $\sigma_{\mathrm{ep}, 1}$ is the extinction coefficient at a wavelength of $1 \mu \mathrm{m}$. In practice, å is merely the linear regression slope of extinction versus wavelength in $\log -\log$ space (i.e., Eq. 2):

$\stackrel{\mathrm{a}}{=}=-\ln \left(\frac{\sigma_{\mathrm{ep}, \lambda_{1}}}{\sigma_{\mathrm{ep}, \lambda_{2}}}\right) / \ln \left(\frac{\lambda_{1}}{\lambda_{2}}\right)$.

In addition to extrapolating extinction coefficients between wavelengths in the shortwave region, Ångström (1929) also noted that the value of the classical Ångström exponent is a good indicator of aerosol particle size, with $\mathrm{a}<1$ indicative of coarse mode dominated aerosol distributions (FMF less than 0.5), and å $>2$ indicative of fine mode dominated aerosol distributions (FMF greater than 0.5). For example, Kaufman et al. (1994) used it as an indicator of the fraction of small particles to large particles in industrial regimes.

Within a given aerosol environment, the classical Ångström fit relationship appears robust. For example, both Reid et al. (1999) and Smirnov et al. (2002) have been able to use empirically derived relationships between size and the classical Ångström exponent in their studies. While å is commonly reported in aerosol optics papers, Reid et al. (1999) noted, based on modeling and observations from Reid et al. (1998), that such a formulation is problematic as the classical Ångström fit is heavily wavelength dependent. For red to near-infrared wavelengths, å adequately represents a mix of fine and coarse mode influences that becomes progressively more coarse mode dominated as the wavelength increases. In the green or blue spectral region fine particle size and refractive index become increasingly more important in determining the value of å. Indeed, the aerosol chemistry dictates the refractive indices of the aerosols, as well as their hygroscopic growth (presuming the measurements were made at a $\mathrm{RH}>\sim 30 \%$ ) which can further impact the size distribution and the refractive indices (Tang, 1996). When the entire AERONET data set of AOD was examined, Eck et al. (1999) noted significant departures from the classic Ångström fit, supported by more theoretical studies by Schuster et al. (2005). 
Table 1. Campaign overview.

\begin{tabular}{|c|c|c|}
\hline Campaign & ACE-Asia & VOCALS \\
\hline Location & Western North Pacific east of Japan & $\begin{array}{l}\text { Southeast Pacific Ocean along the Peruvian and Chilean } \\
\text { coast }\end{array}$ \\
\hline Period & March to April 2001 & October to December 2008 \\
\hline Research vessel & NOAA R/V Ronald H. Brown & NOAA R/V Ronald H. Brown \\
\hline Nephelometer & $\begin{array}{l}\text { One nephelometer }(\lambda=450 \quad 550, \text { and } 700 \mathrm{~nm}) \\
\mathrm{RH} \approx 55 \%\end{array}$ & $\begin{array}{l}\text { Two nephelometers }(\lambda=450,550, \text { and } 700 \mathrm{~nm}) \\
\mathrm{RH} \approx 60 \%\end{array}$ \\
\hline PSAP & One PSAP $(\lambda=550 \mathrm{~nm}) ; \mathrm{RH} \approx 55 \%$ & Two PSAPs $(\lambda=467,530$, and $660 \mathrm{~nm}) ; \mathrm{RH} \leq 25 \%$ \\
\hline Impactor cutoff & $\begin{array}{l}\text { The primary inlet was outfitted with two impactors with } \\
D_{50} \% \text {, aero }=1.1 \mu \mathrm{m} \text { and } D_{50} \% \text {, aero }=10 \mu \mathrm{m} \text {. An auto- } \\
\text { mated valve switched between the two impactors every } \\
15 \mathrm{~min} \text {. }\end{array}$ & $\begin{array}{l}\text { An initial } D_{50 \% \text {, aero }}=10 \mu \mathrm{m} \text { impactor was placed at } \\
\text { the primary inlet and a second impactor with a cutoff } \\
\text { at } D_{50 \% \text {, aero }}=1.0 \mu \mathrm{m} \text { was placed downstream of one } \\
\text { nephelometer and one PSAP. }\end{array}$ \\
\hline $\begin{array}{l}\text { Estimated error of the } \\
\text { extinction coefficient }\end{array}$ & $\begin{array}{l} \pm 14 \% \text { at the } 95 \% \text { confidence level for an averaging } \\
\text { period of } 30 \mathrm{~min} \text { (Quinn and Bates, 2005) }\end{array}$ & $\pm 5 \%$ for an averaging period of $60 \mathrm{~min}(\mathrm{PMEL})$ \\
\hline Air masses encountered & $\begin{array}{l}\text { Complex mixtures of marine, volcanic, pollution and/or } \\
\text { dust sources originating from Asia (Quinn and Bates, } \\
\text { 2005) }\end{array}$ & $\begin{array}{l}\text { Marine regimes with periods of polluted continental air } \\
\text { originating from South America (Hawkins et al., 2010) }\end{array}$ \\
\hline
\end{tabular}

The SDA methodology was developed as an alternative method for extracting fine and coarse mode AOD at a reference wavelength from the total AOD spectrum. The method hinges on the use of a polynomial fit to three or more appropriately spaced wavelengths to capture the first and second derivatives of total AOD $\left(\tau_{\mathrm{T}}\right)$ versus wavelength, specifically $\alpha(\lambda)=-\mathrm{d} \ln \tau_{\mathrm{T}}(\lambda) / \mathrm{d} \ln \lambda$ and its spectral derivative $\alpha^{\prime}(\lambda)=$ $\mathrm{d} \alpha(\lambda) / \mathrm{d} \ln \lambda$ (e.g., "curvature"; Eck et al., 1999; Reid et al., 1999; O'Neill et al., 2001b). It is important to note that $\alpha$ is the differential calculus analogue of å: the spectral derivative $\alpha$ is a pure derivative computed at a specific wavelength from a (differentiable) polynomial fit to $\tau_{\mathrm{T}}(\lambda)$, while å is a regression-based average (or approximate) derivative across what is usually a relatively large wavelength range.

The SDA algorithm was further refined to exploit the increased spectral range (UV to shortwave infrared or SWIR wavelength) available in the most recent generation of AERONET instruments (O'Neill et al., 2008). This algorithm (SDA+) is an extension of the SDA that employs spectral fits to (1) the SDA fine mode outputs of $\tau_{\mathrm{f}}\left(\lambda_{\text {ref }}\right), \alpha_{\mathrm{f}}\left(\lambda_{\text {ref }}\right)$, and $\alpha_{\mathrm{f}}^{\prime}\left(\lambda_{\text {ref }}\right)$ at the reference wavelength $\left(\lambda_{\text {ref }}\right)$ of $500 \mathrm{~nm}$; (2) an empirically derived relation for the spectral position and amplitude of the peak in $\alpha_{\mathrm{f}}(\lambda)$; and (3) the asymptotic, long-wavelength limits of the fine mode spectrum (ibid). The fitted outputs of $\tau_{\mathrm{f}}(\lambda), \alpha_{\mathrm{f}}(\lambda)$, and $\alpha_{\mathrm{f}}^{\prime}(\lambda)$ are then used to derive the analogue coarse mode parameters from the fundamental bi-modal relations for $\tau(\lambda), \alpha(\lambda)$, and $\alpha^{\prime}(\lambda)$. The original SDA+ motivation of extending the range of input wavelengths into the SWIR was not a factor in the analysis of Sect. 4 as our extinction coefficient data is limited to the visible spectral region. In principle one could employ the SDA using a spectrum of reference wavelengths to do the same thing. However, the use of explicit constraints on the fine mode spectrum ensures that the SDA+ output is more spectrally coherent, even in this limited input spectral range.

This SDA+ parameterization, while originally developed for application to AOD measurements, is readily transferable to extinction coefficient analysis by the simple expedient of replacing $\tau$ with $\sigma_{\mathrm{ep}}$. First and second derivatives of the spectral extinction coefficient can be computed using a secondorder spectral polynomial fit to the three measurement channels $(450,550$, and $700 \mathrm{~nm})$, and fine and coarse mode scattering and extinction coefficients can be extracted from these direct measurements. The accuracy of this novel application is easily assessed as the SDA+ output can be compared to direct measurements of the aerosol fine and coarse mode scattering and extinction coefficients made during the field campaigns presented in this paper.

\section{Missions overview and design}

This paper will examine the results of the SDA+ calculations when applied to eight NOAA-PMEL (National Oceanic and Atmospheric Administration - Pacific Marine Environmental Laboratory) data sets collected in multiple marine aerosol regimes. These eight campaigns were selected from all NOAA-PMEL field campaigns with published data (http: //saga.pmel.noaa.gov/data/), where total and submicron extinction or scattering coefficients were measured. We initially focus on two disparate data sets representing two hemispheres, one containing highly polluted marine air and the other relatively clean background marine air, so we can observe the SDA+ performance in high and low extinction regimes. These data were collected from research vessels operated by PMEL during two missions: Aerosol 
Characterization Experiment - Asia (ACE-Asia); and VAMOS (Variability of the American MOnsoon Systems, an international CLIVAR program) Ocean-Cloud-AtmosphereLand Study (VOCALS).

The NOAA Research Vessels (R/Vs) were outfitted with a multitude of instruments to measure the chemical and physical properties of the in situ aerosols. The primary aerosol inlet was located in a mast at the bow of the ship $18 \mathrm{~m}$ a.s.l. The mast was capped with an inlet nozzle that rotated into the relative wind to minimize the loss of large particles. Air was pulled at a rate of $1 \mathrm{~m}^{3} \mathrm{~min}^{-1}$ and heated to a set RH (see Table 1 for specific RH values for each campaign) (Quinn and Bates, 2005).

Each $\mathrm{R} / \mathrm{V}$ contained a TSI integrating three-wavelength nephelometer (Model 3563) $(\lambda=450,550$, and $700 \mathrm{~nm})$ and a Radiance Research particle soot absorption photometer (PSAP) located downstream of the nephelometer. During ACE-Asia, there was only one dedicated $3-\lambda$ nephelometer and one dedicated 1- $\lambda$ PSAP. A valve upstream of the two instruments switched between an impactor with a $10 \mu \mathrm{m}$ aerodynamic diameter cutoff ( $D_{50 \% \text {, aero }}$ ) and an impactor with $D_{50 \% \text {, aero }}=1.1 \mu \mathrm{m}$ every $15 \mathrm{~min}$, allowing for discrete measurements of sub- $10 \mu \mathrm{m}$ and sub- $1.1 \mu \mathrm{m}$ extinction coefficients. The VOCALS campaign had two dedicated $3-\lambda$ nephelometers and $3-\lambda$ PSAPs, and an impactor with a $1 \mu \mathrm{m}$ diameter cutoff was placed downstream of the first pair of instruments, permitting simultaneous measurement of sub-10 $\mu \mathrm{m}$ and sub-1.0 $\mu \mathrm{m}$ extinction coefficients. The nephelometers were zeroed several times throughout the campaign using filtered air, and truncation errors and non-Lambertian illumination errors were corrected using the method described by Anderson and Ogren (1998). The PSAPs were calibrated and corrected for scattering artifacts and deposit spot size as detailed in Bond et al. (1999). Values for both instruments were reported at $\mathrm{STP}\left(0{ }^{\circ} \mathrm{C}\right.$ and $\left.1013 \mathrm{mb}\right)$ over an averaging period of $60 \mathrm{~min}$. Table 1 provides more details about the two campaigns.

The wavelengths of the absorption coefficient measurements were matched to those of the measured scattering coefficients, using the classical absorption Ångström exponent $\left(\stackrel{\circ}{a p}_{\mathrm{a}}\right)$ :

$\stackrel{\circ}{\mathrm{ap}}=-\frac{\log \left(\frac{\sigma_{\mathrm{ap}, 2}}{\sigma_{\mathrm{ap}, 1}}\right)}{\log \left(\frac{\lambda_{2}}{\lambda_{1}}\right)}$,

where $\sigma_{\mathrm{ap}, i}$ is the particle absorption coefficient at wavelength $\lambda_{i}$. During ACE-Asia, when a measured classical absorption Ångström exponent was unavailable due to the measurement of the absorption coefficient at only one wavelength, $\stackrel{\mathrm{a}}{\text { ap }}_{2}=1.5$ was used, except for dust dominated aerosol events (fine mode extinction accounts for less than $25 \%$ of total extinction), where $\stackrel{\circ}{a p}_{\text {ap }}=2$ was used (Bergstrom et al., 2007; Eck et al., 2010).
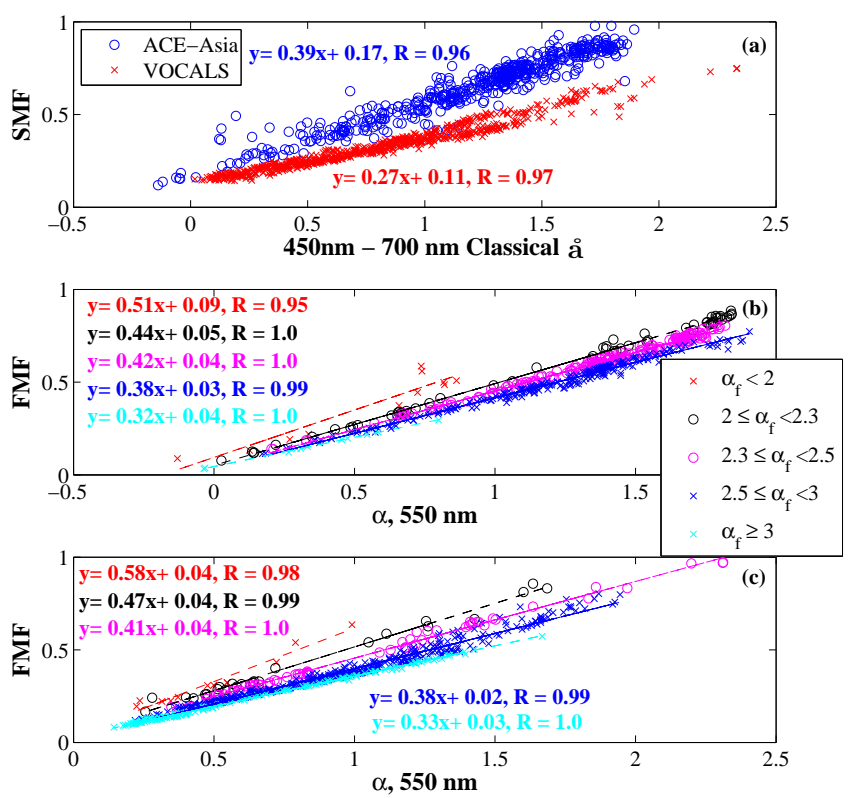

Figure 1. Correlation between (a) the classical Ångström coefficients (å) and the measured submicron fraction (SMF) extinction for ACE-Asia and VOCALS and stratification of the spectral derivative Ångström $(\alpha)$ with calculated fine mode fraction (FMF) during the (b) ACE-Asia and (c) VOCALS campaign.

\section{Results and analysis}

The ACE-Asia and VOCALS data sets represent a vast swath of the aerosol particle variability in the marine atmosphere. Located off the coast of Asia, the ACE-Asia cruise experienced clean marine, pollution, dust and volcanic conditions, and nearly every possible combination thereof. For VOCALS, the environment was clean marine with persistent stratus above and injections of pollution from coastal Chile and Peru. The two missions represent two extremes from the PMEL cruise data set collection. We begin our analysis in Sect. 4.1 with our baseline hypotheses, namely, that as is commonly assumed in the community, the classical Ångström exponent and SMF are linearly proportional. Here we examine differences between the two parameters for the two missions. In Sect. 4.2 we examine in detail the ACE-Asia campaign data and verify the application of SDA + for a host of conditions. From there, we examine VOCALS in Sect. 4.3, which, with its very clean conditions, is perhaps the more challenging data set to analyze. Section 4.4 applies what we have learned to six more data sets collected by NOAA-PMEL and discusses best practices for future application of SDA+ to scattering and extinction coefficient measurements.

Relationships between the Angström exponent and fine mode fraction as a first analysis step, the nephelometer + PSAP-derived classical Ångström exponent (å) was compared to the nephelometer + PSAP-measured SMF for the ACE-Asia and VOCALS cruises. In order to present the most 
accurate depiction of the relationship, the VOCALS $450 \mathrm{~nm}$ nephelometer channel was increased by $5 \%$ as is explained in Sect. 4.3. Figure 1 presents the relationship for the entire wavelength span (450-700 nm). Important features are immediately apparent. First, while the relationships are indeed strong within each campaign $(R>0.96)$, there is a clear difference in the two missions' data populations: slope differences are $31 \%$. For entirely coarse mode dominated environments (dust for ACE-Asia, and sea salt for VOCALS), both å values originate near zero, a well-known behavior. But for fine mode dominated environments the relationships diverge markedly. Using the classical Ångström relationship for ACE-Asia, a SMF extinction of 1.00 is associated with a $450-700 \mathrm{~nm}$ classical $\stackrel{\mathrm{a}}{=}=2.13$, but the same $\mathrm{a}=2.13$ is associated with a SMF of 0.68 in VOCALS. Furthermore, it is evident that there are cases in the marine environment when the assumption that $\mathrm{a}<1$ indicates a coarse mode dominated aerosol distribution is flawed. Within the ACE-Asia data set the cross over from coarse to fine mode dominated extinction (SMF extinction $>0.5$ ) occurs at $\stackrel{a}{=}=0.84$.

The FMF and the SMF are intrinsically related but their relationship as a function of Angstrom exponent differs in detail for different reasons. Figure $1 \mathrm{~b}$ and $\mathrm{c}$ show the FMF versus the SDA $+\alpha$ at $550 \mathrm{~nm}$ for the ACE-Asia and VOCALS data sets, respectively. As indicated by Eq. (1) of O'Neill et al. (2003):

$$
\begin{aligned}
\eta & =\frac{\alpha-\alpha_{\mathrm{c}}}{\alpha_{\mathrm{f}}-\alpha_{\mathrm{c}}} \\
& =\left(\frac{1}{\alpha_{\mathrm{f}}-\alpha_{\mathrm{c}}}\right) \alpha+\left(\frac{-\alpha_{\mathrm{c}}}{\alpha_{\mathrm{f}}-\alpha_{\mathrm{c}}}\right),
\end{aligned}
$$

the dispersion of the FMF ( $\eta$ ) versus $\alpha$ scattergrams can be, at least partly, described by the variation in fine mode particle size (by the variation in $\alpha_{\mathrm{f}}$, where the coarse mode spectral derivative, $\alpha_{\mathrm{c}}$, is relatively constant, nominally taken as -0.15 in the SDA+ retrieval). An increase in $\alpha_{\mathrm{f}}$ will result in a smaller slope and intercept. This can be seen in Fig. 1b and $\mathrm{c}$ where the relationship is stratified into ranges of increasing $\alpha_{\mathrm{f}}$ or decreasing particle size. The regression coefficients of the linear fits seen in the graphs is smallest for $\alpha_{\mathrm{f}}<2$ : this is understandable since small values of $\alpha_{\mathrm{f}}$ represent a regime where the retrieval is less dependable (where $\alpha_{\mathrm{f}}$ becomes progressively more confounded with $\alpha_{\mathrm{c}}$ and its associated uncertainty).

\subsection{SDA+ results: ACE-Asia $30-40^{\circ} \mathrm{N}$ western Pacific Ocean - polluted regime}

In our first in-depth analysis of the application of the SDA+ method to in situ data, 60 min averages of $\mathrm{PM}_{10} 3-\lambda$ extinction coefficient measurements $(450,550$, and $700 \mathrm{~nm})$ as measured by a nephelometer and PSAP during ACE-Asia were used, rather than spectral AOD, as inputs to the code. $\mathrm{SDA}+$ was then used to calculate the fine and coarse mode extinction coefficients, which were in turn compared to fine
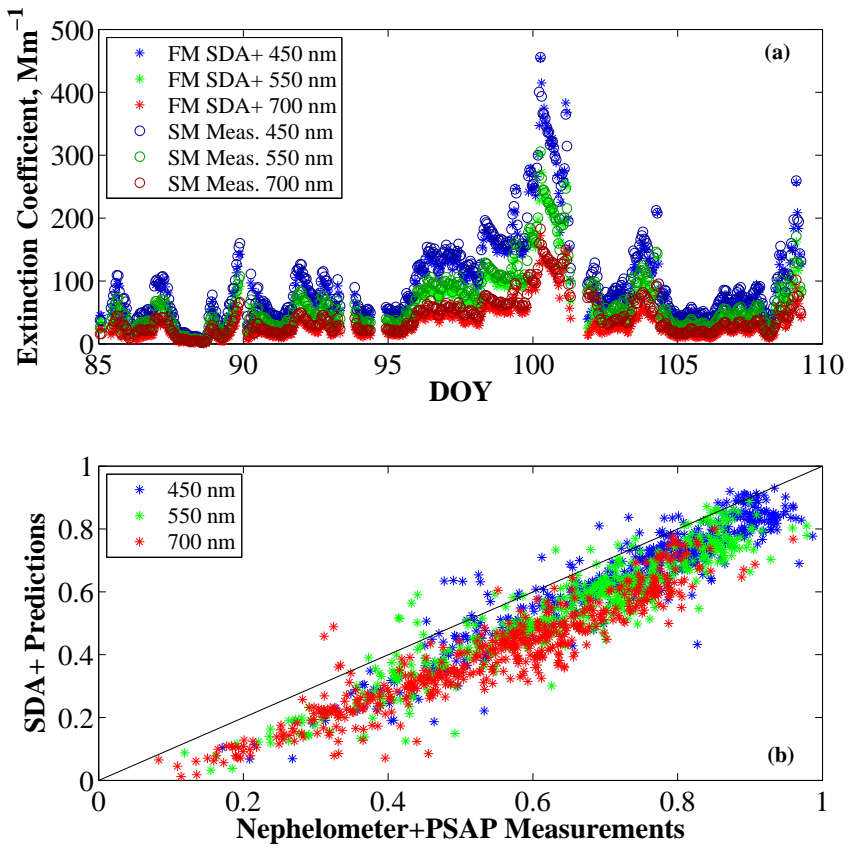

Figure 2. A time series (a) of the measured submicron mode (SM) and SDA+-calculated fine mode (FM) extinction coefficient aboard the R/V Ronald H. Brown (PMEL) during the ACE-Asia campaign. Bottom graph (b) shows fine mode fraction extinction predicted by SDA+ versus the equivalent submicron fraction derived from PSAP and nephelometer extinction coefficient measurements. Plots for scattering coefficient predictions and measurements show similar agreements (see Supplement). A one-to-one line is provided for reference in (b). Fit statistics are found in Table 2.

and coarse mode extinction coefficient measurements made by the PSAP and nephelometer (for which the fine and coarse modes were separated by the $1.1 \mu \mathrm{m}$ impactor). Additionally, the SDA+ method was applied solely to the nephelometer results to examine the applicability of SDA+ to predict fine and coarse mode scattering coefficients.

The ACE-Asia data set was collected over a variety of air masses, ranging from relatively clean marine air to highly polluted Asian continental outflow, with periods dominated by dust from the Gobi Desert, dust mixed with pollution from China and/or Korea, and volcanic aerosols mixed with pollution (Quinn et al., 2004). This data set provides us with the greatest opportunity to examine the applicability of the SDA+ methodology to a wide range of environments, aerosol chemistries, and hence particles sizes and indices of refraction.

The mission time series of $1.1 \mu \mathrm{m}$ impactor measured submicron mode (SM) and SDA+-calculated fine mode (FM) extinction coefficient is presented in Fig. 2a while the SDA+-calculated FMF and observed SMF for extinction is presented in Fig. 2b. These results show good agreement between the predicted and observed fine mode extinction coefficients as well as between the extinction-based SMF and 
Table 2. Fit statistics for measured and SDA+ calculated output from Fig. 2.

\begin{tabular}{lrrr}
\hline Statistics - ACE-Asia & $450 \mathrm{~nm}$ & $550 \mathrm{~nm}$ & $700 \mathrm{~nm}$ \\
\hline Correlation coefficient for FM scattering/extinction coefficients & $0.99 / 0.99$ & $0.98 / 0.98$ & $0.96 / 0.97$ \\
RMSE for SMF and FMF scattering/extinction coefficient & $0.10 / 0.10$ & $0.12 / 0.12$ & $0.14 / 0.15$ \\
MBE for SMF and FMF scattering/extinction coefficient & $0.08 / 0.08$ & $0.10 / 0.10$ & $0.13 / 0.14$ \\
\hline
\end{tabular}

FMF. The results, in general, for both extinction and scattering coefficients, for low and high scattering regimes and for fine and coarse mode dominated regimes, were found to give good agreement with low errors (correlation coefficients, root mean square errors (RMSEs) and mean bias errors (MBEs) are reported in Table 2).

Figure 2 and Table 2 overall show that SDA+, with associated correlation coefficients greater than 0.96 , is a viable method for estimating fine mode extinction coefficients when only direct measurements of total extinction coefficients are available. However, there is one obvious bias, namely, the predicted FMF-to-observed SMF ratio generally falls below the one-to-one line in the bottom graphs of Fig. 2 (associated MBE is greater than 0.08). Such a bias was also observed in AERONET sun photometer data when the SDA was compared to the Dubovik and King (2000) retrieved SMF (O'Neill et al., 2003; Eck et al., 2010). That bias was explained by a known fine mode bias in the reference methods: the assumed minimum in the bi-modal size distribution for the Dubovik and King (2000) AERONET inversions. In our case, the SMF is determined by the strict diameter cutoff of an impactor. In both cases, the reference method fails to account for the tails of the full fine and coarse mode particle distributions. The impactor cutoff diameter for ACE-

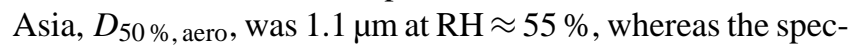
trally based separation of fine mode aerosols used in the $\mathrm{SDA}+$ methodology has no physical cutoff diameter. The encroachment of the physical coarse mode aerosol into diameter regime associated with the measured fine mode scattering described in the introduction would lead to a lower predicted-to-measured value for fine mode extinction coefficient, resulting in SMF extinction values below the one-toone line in the FMF versus SMF graph of Fig. 2b. This bias is observed in the ACE-Asia results.

We can verify this hypothesis for the observed bias through examination of aerosol volume distributions collected alongside the nephelometer and PSAP data during the ACE-Asia cruise. The size distributions were measured using a differential mobility particle sizer (DMPS; diameter range 0.020 to $6.71 \mu \mathrm{m}$ ) and an aerodynamic particle sizer (APS; diameter range 0.5 to $20 \mu \mathrm{m}$ ) where the APSmeasured aerodynamic diameters were converted to Stokes diameters using measured chemistry to calculate the aerosol density. The APS data were corrected for ultra-Stokesian conditions in the instrument jet as well as shape effects (Quinn et al., 2004). Overlapping channels were examined
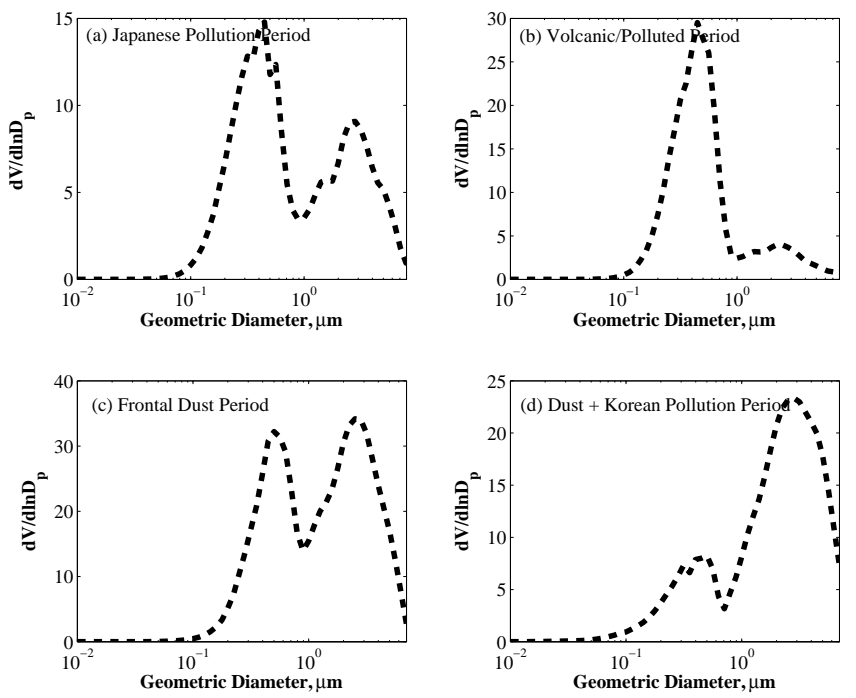

Figure 3. Mean aerosol volume distributions during four periods of observation during the ACE-Asia field campaign.

and the first APS diameter channel with a higher count than the corresponding DMPS channel was used to replace overlapping DMPS channels at that aerosol Stokes diameter and for all larger channels. The measurements were made at an $\mathrm{RH} \approx 55 \%$ (Quinn et al., 2004).

Figure 3 illustrates mean aerosol volume distributions for four of the seven ACE-Asia study periods as defined by Quinn et al. (2004). All seven identified periods had observed minimum distribution values at particle diameters $\left(D_{\mathrm{p}, \min }\right)$ less than $1.1 \mu \mathrm{m}$. For the period consisting primarily of aerosols originating from Japanese pollution sources (DOY: 96.4-99.2), and for the period of observation during the dust frontal passage (DOY: 101.0-101.3), the mean observed $D_{\mathrm{p} \text {, min }}$ between the fine and coarse mode particles was $D_{\mathrm{p}, \min }=0.89 \mu \mathrm{m}$ (Fig. 3a and c). For the period dominated by fine mode volcanic emissions (DOY: 99.3-100.5), the partition was $D_{\mathrm{p} \text {, min }}=1.00 \mu \mathrm{m}$ (Fig. 3b). The coarse mode dominated the period containing dust from China and Mongolia and pollution from the Korean Peninsula (DOY: 101.8103.4), showed a partition between the fine and coarse mode of $D_{\mathrm{p}, \min }=0.71 \mu \mathrm{m}$ (Fig. $3 \mathrm{~d}$ ). It is worth noting that these values are highly dependent on RH. At ambient RHs, the estimated $D_{\mathrm{p} \text {,min }}$ observed from AERONET inversions was greater than $1.5 \mu \mathrm{m}$ (Eck et al., 2005), but this is consistent with the highly hygroscopic pollution aerosols present in this 

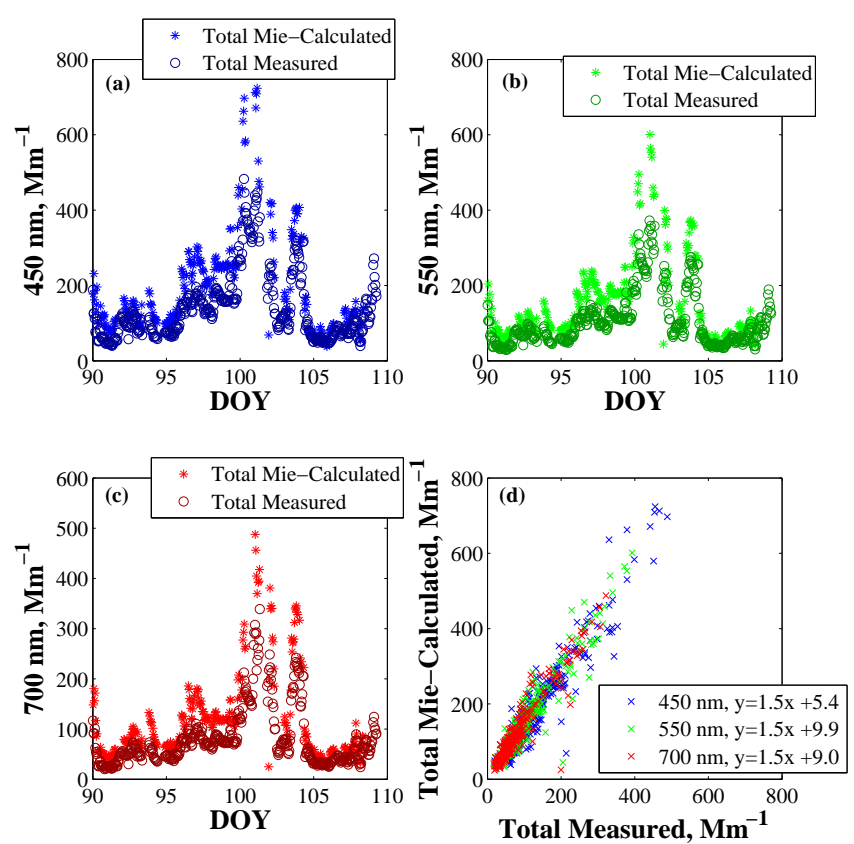

Figure 4. Measured total scattering coefficients from the ACE-Asia field campaign compared to the scattering coefficients calculated using the aerosol size distributions and Mie scattering calculations. The time series shown in (a) through (c) are limited to DOY 90-110 as representative (so as to increase readability).

region and the high ambient RHs observed during the ACE Asia field campaign (Quinn et al., 2004).

To visualize the coarse mode residual $(\triangle \mathrm{CM})$ contained in the submicron mode (SM) scattering coefficients as determined by the $1.1 \mu \mathrm{m}$ impactor, we used a combination of Mie-scattering calculations using various assumed cutoff values $\left(D_{\mathrm{c}}\right)$ and compared these to a ratio of the FM scattering coefficient retrieved using the SDA+ divided by the physically measured ACE-Asia sub-1.1 $\mu \mathrm{m}$ nephelometer scattering coefficients (i.e., FM / SM). The quantity computed using the Mie calculations was the ratio:

$X=\frac{\operatorname{SM}\left(D_{\mathrm{c}}\right)}{\operatorname{SM}\left(D_{\mathrm{ref}}\right)}$,

where $\operatorname{SM}\left(D_{\mathrm{c}}\right)$ and $\mathrm{SM}\left(D_{\text {ref }}\right)$ are the computed scattering coefficients for a variety of $D_{\mathrm{c}}$ test values and the impactor cutoff of $D_{\text {ref }}=1.1$ where the measured particle size distribution was employed for the Mie calculations. Equation (5) can be recast as

$X=\frac{\mathrm{FM}-\Delta \mathrm{FM}\left(D_{\mathrm{c}}\right)+\Delta \mathrm{CM}\left(D_{\mathrm{c}}\right)}{\mathrm{FM}-\Delta \mathrm{FM}\left(D_{\text {ref }}\right)+\Delta \mathrm{CM}\left(D_{\text {ref }}\right)}$,

where $\Delta \mathrm{FM}$ is the FM contribution to the coarse mode extinction due to the portion of the fine mode that extends beyond $D_{\mathrm{c}}$ and $\triangle \mathrm{CM}$ is the portion of $\mathrm{CM}$ that is included in the fine mode integration due to $D_{\mathrm{c}}$. For a given particle size distribution, we expect $X$ to decrease monotonically with decreasing $D_{\mathrm{c}}$, from a value of unity at $D_{\text {ref }}=1.1 \mu \mathrm{m}$ to a value

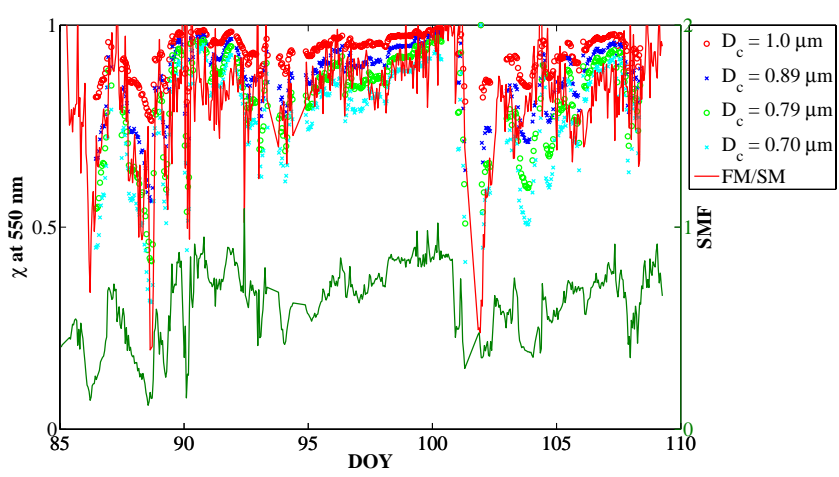

Figure 5. Calculated values of $X=\operatorname{SM}\left(D_{\mathrm{c}}\right) / \mathrm{SM}\left(D_{\text {ref }}\right)$ (four dotted curves). The $X$ output was calculated four times using Mie scattering and measured size distributions, with different values of the cutoff diameter $D_{\mathrm{c}}$. The solid red line is the SDA+-retrieved FM divided by the nephelometer-measured submicron mode $\left(X_{\text {meas }}=\mathrm{FM} / \mathrm{SM}\right)$. The measured submicron fraction $(\mathrm{SMF})$ is included for reference.

of $\mathrm{FM} / \mathrm{SM}$ as $\Delta \mathrm{CM}$ approaches $\Delta \mathrm{FM}$ to values less than FM / SM. Optimal values of $D_{\mathrm{c}}$, for which $X=\mathrm{FM} / \mathrm{SM}$, should be in the neighborhood of $D_{\mathrm{p}, \min }$ (although the SDA+ calculation process is optical and not based purely on the particle size distribution).

In order to verify the quality of our Mie calculations, we first calculated the Mie-scattering coefficients for the measured total aerosol size-distribution and compared the results to the nephelometer-measured scattering coefficients (Fig. 4), achieving adequate agreement (correlation coefficient values above 0.95 ). We then calculated $X$ of Eq. (5) for a variety of cutoff diameters $\left(D_{\mathrm{c}}=1.0,0.89,0.79\right.$, and $0.71 \mu \mathrm{m})$. Thus the variation of $X$ allows us to visualize several possible scenarios of $\triangle \mathrm{CM}$ contained in the fine mode. The results are coherent with the SDA+ retrievals inasmuch as an optimal and realistic $D_{\mathrm{c}}$ value is found for almost all of the measurements in the temporal series of Fig. 5. The variability of the point where $X$ intercepts FM / SM (the red curve of Fig. 5) is expected as the optimal values of $D_{\mathrm{c}}$ and $\triangle \mathrm{CM}$ will change with changes in the aerosol size distribution.

Both in the low FMF cases and the high FMF cases in Fig. 5, we see that there is obvious encroachment of coarse mode aerosols below the $D_{50} \%$, aero $=1.1 \mu \mathrm{m}$ cutoff point for SM scattering coefficient measurements (i.e., that the best match with the FM/SM curve corresponds to $D_{\mathrm{c}}$ values below $1.1 \mu \mathrm{m}$ ). This is an illustrative confirmation of why the nephelometer-measured SMF $\left(\mathrm{SM}_{0}\right)$ was consistently greater than the FMF calculated by the SDA+ (Fig. 2). Indeed, under the ACE-Asia study conditions, the application of the SDA+ algorithm to total nephelometer and PSAP data appears more representative of fine and coarse mode extinction than the actual use of an impactor. 


\subsection{SDA+ sensitivity analysis: VOCALS: $0-22^{\circ} \mathrm{S}$ eastern Pacific Ocean - mixed marine}

The ACE-Asia analysis is a good example of the application of the SDA+ method to an environment with a large concentration of aerosols. The VOCALS field campaign, on the other hand, was much more representative of clean marine air, with occasional spikes in the fine mode extinction coefficient caused by local pollution events such as fossil fuel burning emissions and copper smelter emissions from the coast of Chile and Peru (Hawkins et al., 2010). The VOCALS region fine mode particle size may be larger than most regions globally due to sulfates that are cloud-processed in the persistent Alto Cumulus deck. Eck et al. (2012) show very large retrieved fine mode radius values at the Arica site on the coast of Chile for ambient conditions. These retrievals were associated with very large curvature of the AOD spectra from 380 to $870 \mathrm{~nm}$. The lower aerosol concentrations measured during VOCALS resulted in much lower total extinction coefficients, with means of 30,26 , and $22 \mathrm{M} \mathrm{m}^{-1}$, for 450,550 and $700 \mathrm{~nm}$, respectively, and a mean $550 \mathrm{~nm}$ absorption coefficient of $2.1 \mathrm{M} \mathrm{m}^{-1}$, as compared to the ACE-Asia data set, with mean total extinction coefficients of 135,126 , and $91 \mathrm{M} \mathrm{m}^{-1}$ and a $550 \mathrm{~nm}$ absorption coefficient of $7.3 \mathrm{M} \mathrm{m}^{-1}$.

The agreement between SDA+-predicted and observed fine mode extinction coefficients, Fig. 6a, and SMF extinction and FMF extinction, Fig. 6b, is good, but deteriorates in high FMF regimes (associated error statistics are reported in Table 3, top). There is an overprediction of the fine mode extinction and scattering coefficients at all three wavelengths in high FMF extinction regimes, most particularly in the $700 \mathrm{~nm}$ channel. The same pattern is observed with the scattering coefficient (see Supplement).

Investigation of the biases evident in Fig. 6a led us to examine the sensitivity of the second-order fit in the SDA+ code to small errors in the measurements. We found that particularly at such small levels of total extinction, small input errors can produce large errors in the resulting calculations. Thus, a single wavelength error could have dramatic consequences to the application of the SDA+ method. To test the reproducibility of the (scattering dominated) measured extinction coefficient in the clean marine environment, we performed forward calculations of the scattering coefficient from the aerosol size distributions measured during the VOCALS campaign, and compared them to the nephelometer measurements.

As in the ACE-Asia campaign, the size distributions were measured using the combined results from the DMPS and the APS. For VOCALS, the measurements were made at an $\mathrm{RH} \approx 60 \%$. The coarse mode was assumed to be sea salt with a refractive index of 1.54 and a growth factor of 1.75 at $60 \%$ $\mathrm{RH}$, and the fine mode was assumed to be ammonium sulfate with a refractive index of 1.53 and a growth factor of 1.30 at $60 \%$ RH (Tang et al., 1996).
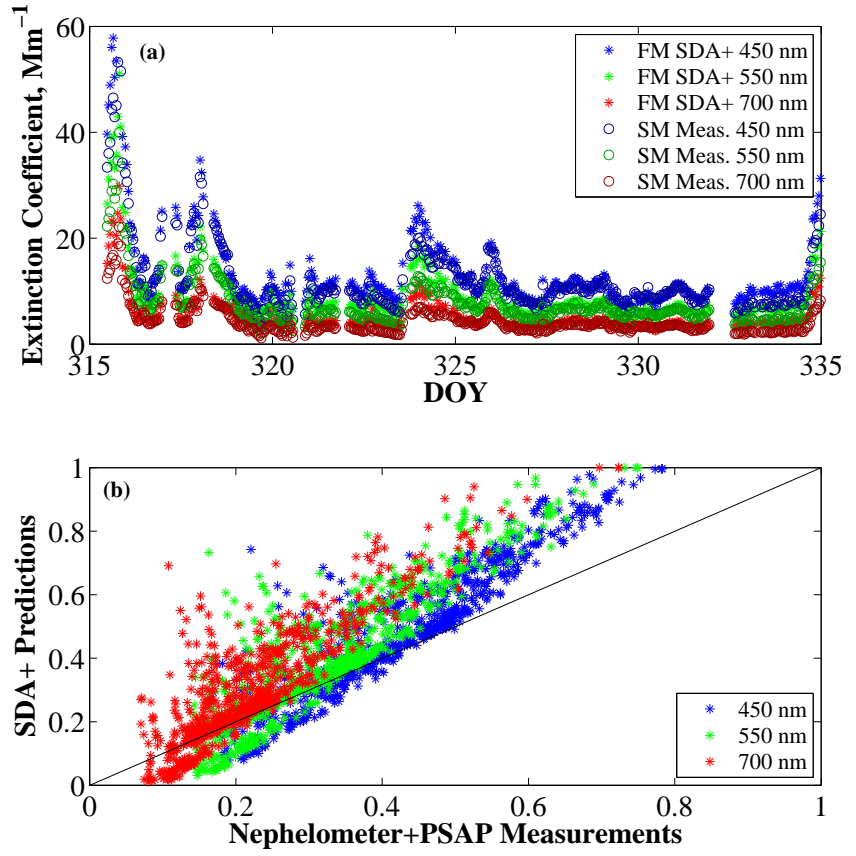

Figure 6. A time series (a) of the measured submicron mode (SM) and SDA+-calculated fine mode (FM) extinction coefficient aboard the R/V Ronald H. Brown (PMEL) during the VOCALS campaign. Bottom graph (b) shows fine mode fraction extinction predicted by SDA+ versus the equivalent submicron fraction derived from PSAP and nephelometer extinction coefficient measurements. Plots for scattering coefficient predictions and measurements show similar agreements. A one-to-one line is provided for reference in (b). Fit statistics are found in Table 3 (top).

The results of Mie calculations compared to the nephelometer measurements are shown in Fig. 7. While it is dangerous to draw too many conclusions from Fig. 7 due to large uncertainties in the coarse mode size distribution (Reid et al., 2006), and an estimated uncertainty in the calculated scattering coefficient of $\pm 35 \%$ (Quinn et al., 2004), we can clearly see the three channels do not respond similarly. Because of the large uncertainty it is difficult to specify if the red channel is underpredicting or the blue channel is overpredicting the scattering coefficient, but our knowledge that the SDA+ is overpredicting fine mode aerosol extinction (Fig. 6b) leads us to conclude there is excessive curvature in the nephelometer output. Thus, we increased the $450 \mathrm{~nm}$ measured extinction coefficient by a mere $5 \%$ and reran the SDA+ code. The results are shown in Fig. 8 with associated error statistics found in Table 3 (bottom), and demonstrate a significant improvement over the original results, with lower RMSEs in all three channels. The reader will recall that the outputs for all channels are affected by the change in the $450 \mathrm{~nm}$ channel because the second-order fit is applied across all three channels within the SDA+ methodology to calculate fine mode scattering and extinction coefficients. 
Table 3. Fit statistics for measured and SDA+ calculated output from Figs. 6 and 8.

\begin{tabular}{lrrr}
\hline Statistics - VOCALS & $450 \mathrm{~nm}$ & $550 \mathrm{~nm}$ & $700 \mathrm{~nm}$ \\
\hline Correlation coefficient for FM scattering/extinction coefficient & $0.98 / 0.98$ & $0.96 / 0.96$ & $0.91 / 0.91$ \\
RMSE for SMF and FMF scattering/extinction coefficient & $0.12 / 0.12$ & $0.14 / 0.14$ & $0.15 / 0.14$ \\
MBE for SMF and FMF scattering/extinction coefficient & $-0.07 /-0.07$ & $-0.09 /-0.08$ & $-0.09 /-0.09$ \\
\hline Statistics-corrected VOCALS & $450 \mathrm{~nm}$ & $550 \mathrm{~nm}$ & $700 \mathrm{~nm}$ \\
\hline Correlation coefficient for FM scattering/extinction coefficient & $0.99 / 0.99$ & $0.98 / 0.98$ & $0.97 / 0.97$ \\
RMSE for SMF and FMF scattering/extinction coefficient & $0.09 / 0.08$ & $0.07 / 0.07$ & $0.05 / 0.06$ \\
MBE for SMF and FMF scattering/extinction coefficient & $-0.07 /-0.06$ & $-0.02 /-0.02$ & $-0.01 / 0.01$ \\
\hline
\end{tabular}
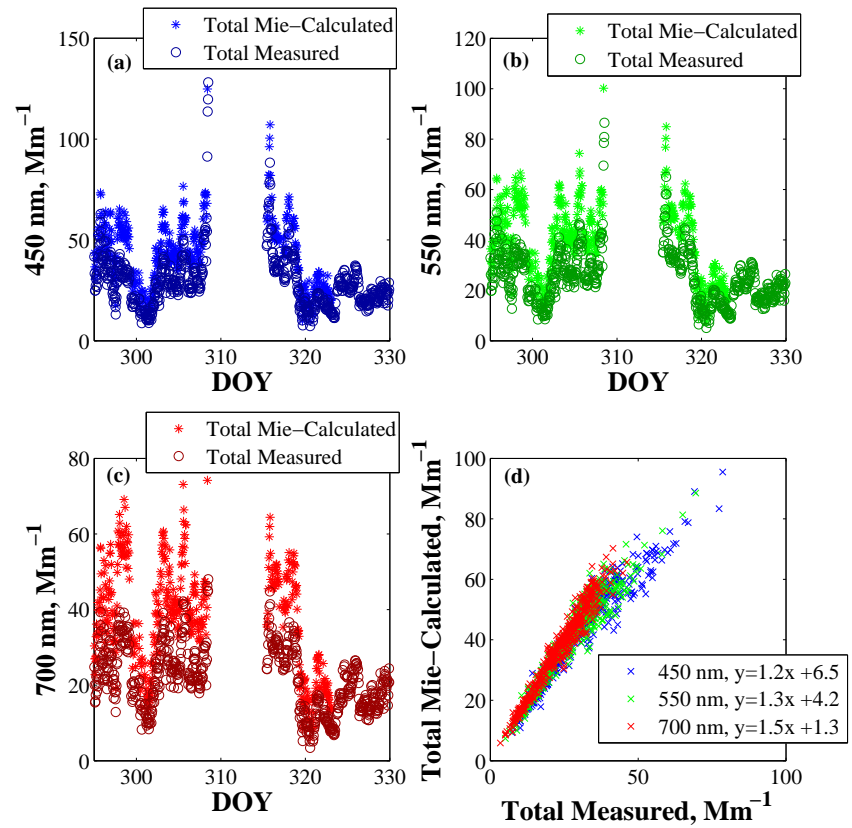

Figure 7. Measured total scattering coefficient from the VOCALS field campaign compared to the scattering coefficient calculated using the aerosol size distributions and Mie scattering calculations.

The cause for the error within the $450 \mathrm{~nm}$ channel is attributed to a slight degradation (now rectified) of the nephelometer detected during the VOCALS field campaign due to the PMT or the firmware controlling the channel. While difficult to quantify the exact level of degradation in the VOCALS data set, $5 \%$ is a reasonable first estimate, and is within the uncertainty of the calibration corrections. It is worth reiterating that the SDA+ code was originally developed for the AERONET sensors, which have four to eight channels spanning the solar spectrum from the near IR to the UV. Here we are applying a second-order fit to three channels in the visible spectrum (i.e., there is no data redundancy to mitigate any single channel error). This means that the second-order fit of the SDA+ code is sensitive to small errors in the measurements: a presumed error of $5 \%$ in the scattering coefficient in one channel can result in a significant
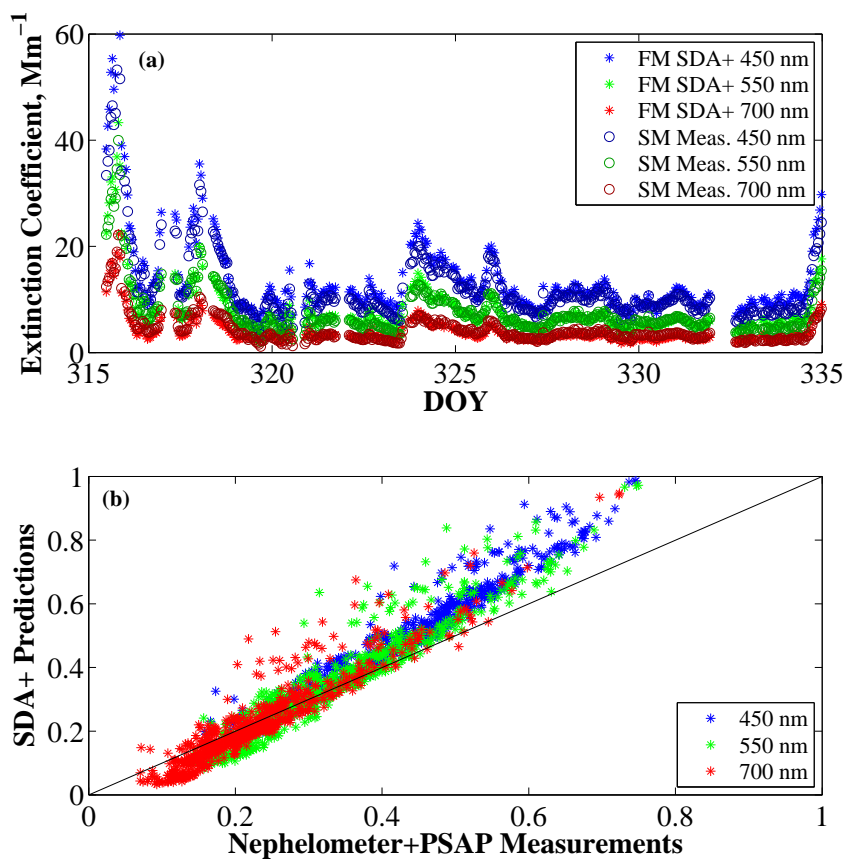

Figure 8. A time series (a) of the corrected measured submicron mode (SM) and SDA+-calculated fine mode (FM) extinction coefficient aboard the R/V Ronald H. Brown (PMEL) during the VOCALS campaign. Bottom graph (b) shows fine mode fraction extinction predicted by SDA+ versus the equivalent submicron fraction derived from PSAP and corrected nephelometer extinction coefficient measurements. Plots for scattering coefficient predictions and measurements show similar agreements. A one-to-one line is provided for reference in (b). Fit statistics are found in Table 3 (bottom).

increase in the RMSE of the output of the SDA+ code. Thus, while we believe the physics of the SDA+ retrieval is sound, this exercise demonstrates the necessity for reducing uncertainties in the field measurements to the greatest extent possible. 


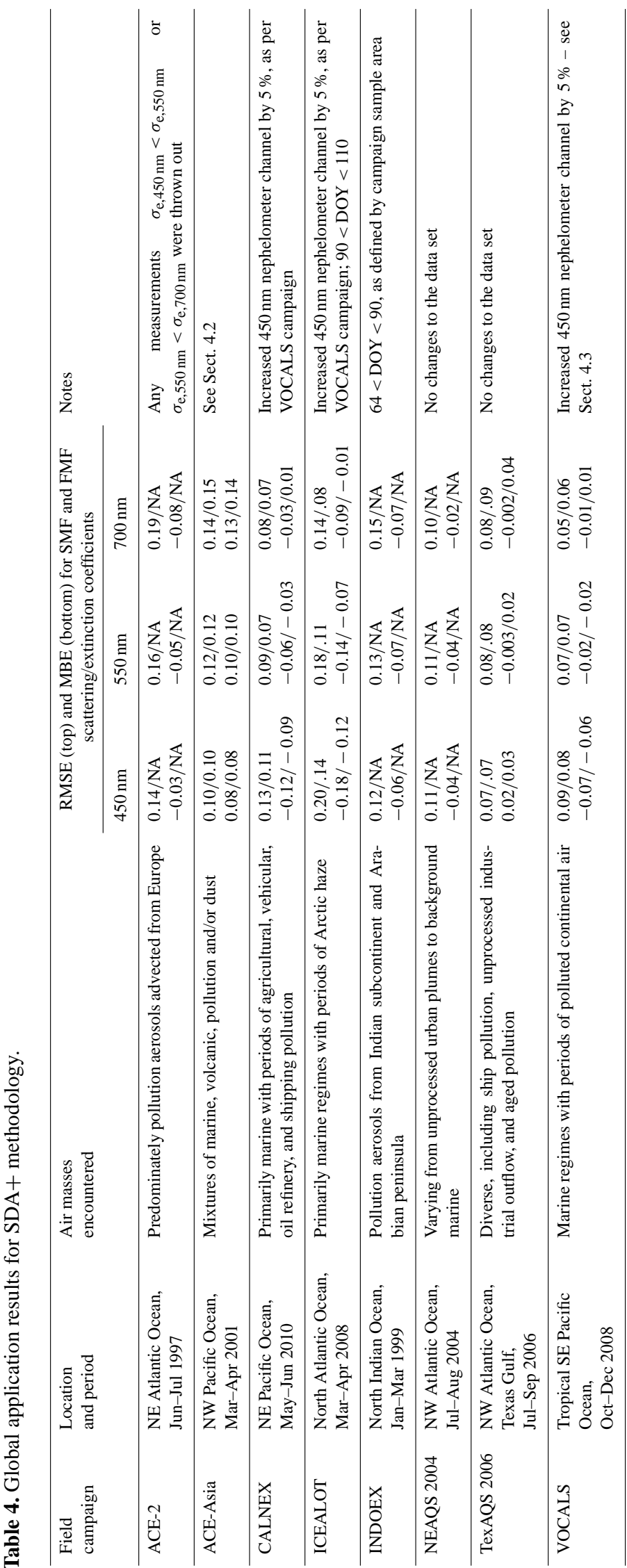

\subsection{Global application of the SDA+}

In order to further test our methodology on data sets spanning the globe, we applied the SDA+ to every available field campaign performed by NOAA-PMEL (http://saga.pmel.noaa. gov/data/), where total and submicron extinction or scattering coefficients were measured (not every campaign listed on the website reported total and submicron scattering or extinction coefficient measurements). Details of the instrumental setups are found at the NOAA-PMEL website. These field campaigns along with their location and campaign period are summarized in Table 4. Three of the field campaigns were lacking measurements of either submicron absorption or total absorption, so the SDA+ methodology was applied only to the scattering coefficient measurements. ACE-2, ACE-Asia, and INDOEX used a single dedicated $3-\lambda$ TSI nephelometer $(450,550,700 \mathrm{~nm})$ and two impactors, one with a cutoff diameter of $1.1 \mu \mathrm{m}$ and the other with a cutoff diameter of $10 \mu \mathrm{m}$, which alternated positions upstream of the nephelometer every $15 \mathrm{~min}$. ACE-Asia also had a 1- $\lambda$ PSAP downstream of the filters, as described in Sect. 3. These measurements were made at $55 \% \mathrm{RH}$. The remaining campaigns had two 3- $\lambda$ nephelometers $(450,550$, and $700 \mathrm{~nm})$ which measured at an RH of approximately $60 \%$. The first nephelometer measured scattering due to aerosols with aerodynamic diameters of less than $10 \mu \mathrm{m}$ and the second measured scatter due to aerosols with aerodynamic diameters of less them $1 \mu \mathrm{m}$. Except for the NEAQS 2004 campaign, each campaign also had two PSAPs (radiance research) that reported sub- $10 \mu \mathrm{m}$ and sub- $1 \mu \mathrm{m}$ absorption at three wavelengths $(467,530$, and $660 \mathrm{~nm})$ and an RH ranging between 25 and $60 \%$. The measured absorption coefficients were subsequently corrected to match the nephelometer wavelengths using the classical absorption Ångström coefficient, but any effects due to differing RHs were ignored. All measurements were averaged over $60 \mathrm{~min}$.

Some modifications were necessary to the input data set, as described in the "notes" column of Table 4. Primarily the slight deterioration of the $450 \mathrm{~nm}$ nephelometer channel described in Sect. 4.3 was evident in two campaigns in the subsequent years following VOCALS. Furthermore, during ACE-2, there were periods where the measured scattering coefficients from the 450,550, and $700 \mathrm{~nm}$ channel appeared to have an inverse curvature. While it is possible that this is a real phenomenon (e.g., fog droplets present), it is also possibly an error in instrumental calibration. Only measurements where $\sigma_{\mathrm{e}, 450 \mathrm{~nm}}>\sigma_{\mathrm{e}, 550 \mathrm{~nm}}$ and $\sigma_{\mathrm{e}, 550 \mathrm{~nm}}>\sigma_{\mathrm{e}, 700 \mathrm{~nm}}$ were used. The results presented in Table 4 show the good agreement between measured and SDA+-calculated fine mode scattering and extinction coefficients across multiple oceans, hemispheres, and marine environments, with the strong caveat that measured total scattering and extinction coefficients must be accurate for the SDA+ methodology to work. 


\section{Discussion and conclusions}

The successful use of the SDA+ algorithm applied to nephelometer and PSAP data, as well as to nephelometer data alone, not only verifies the application of the method to in situ data, but by inference verifies the method as a whole. Indeed, while the application of the SDA+ algorithm is consistent with the more comprehensive extinction-sky radiance retrievals of Dubovik and King (2000), previous assessments of the SDA+ method has largely been by inference. Here we demonstrate the consistency of the optical method against a true benchmark and thus verify the method as a whole. Clearly, the SDA+ methodology is suitable for separating the fine and coarse mode extinction coefficients from measured total extinction, with low RMSEs for high and low aerosol extinction regimes, with large and small FMF and for data sets spanning the globe. However, there are several caveats for interpreting any SDA+ data set derived in general as well as specifically from nephelometer and PSAP data sets.

Interpretation of any error in the SDA+ calculated FMF as compared to measurements must take into account the cutoff diameter for the measured fine mode extinction coefficients. As the coarse mode aerosol population frequently creeps below conventional cutoff diameters, and as the SDA+ methodology has no assumed aerosol cutoff diameter, the SDA+ calculations in some instances may be more relevant (within a context of bi-modal distributions that extend beyond the artificial particle size limits imposed by fine-mode inlet filter) than the measured SMF.

Perhaps the most pressing requirement for the application of the SDA+ (and SDA) is scrupulous attention to instrument calibration. Without a doubt, the previous successful application of the SDA method to AERONET sun photometer data is largely due to the networks well-earned reputation of solid instrument calibration. The breadth of wavelengths used from the near UV into the near IR increases confidence in curvature signatures while reducing the influence of isolated channel mis-calibration. In contrast, the second-order (zero redundancy) fit of the SDA+ method to the measured extinction coefficients at the three wavelengths in the visible spectrum commonly used by the nephelometer and PSAP can cause the SDA+ output to be extremely sensitive to small errors in the extinction coefficient input. This underscores the need for careful calibration of all field instruments.

Ultimately, the SDA + methodology shows significant improvement over current status quo of using Ångström exponents to estimate the contribution of fine mode aerosols to scattering and extinction coefficients where direct measurements of fine and coarse mode contributions are not available. Accurate use of Ångström exponents to estimate the contribution of the fine mode aerosols to the total scattering or extinction regime requires measurements of the relationship between the two to be taken inasmuch as the slope between the Ångström exponent and the SMF can change, due to changes in aerosol size distribution, chemistry, and hygroscopicity. Since this feature is, at least in part, built into the SDA+ (cf. Fig. 1) then its performance is, for this reason and because it accounts for second-order spectral curvature, an improvement over the current status quo method. Thus the SDA+ methodology can increase our knowledge of fine mode scattering and extinction and the contribution of anthropogenic aerosols to total aerosol extinction in global and historical data sets which currently lack explicitly measured fine and coarse mode data set.

\section{The Supplement related to this article is available online at doi:10.5194/amt-7-3399-2014-supplement.}

Acknowledgements. Funding for this effort was initiated under a grant from the office of Naval Research Code 35, with completion by Code 32 . We are grateful to NOAA for the collection and use of their voluminous data records. PMEL's contribution to this work was provided by NOAA's Climate Program Office. Funding for N. T. O'Neill was provided by the National Sciences and Engineering Research Council of Canada and Environment Canada. T. F. Eck's funding was provided by the NASA AERONET Program.

Edited by: H. Herrmann

\section{References}

Anderson, T. A. and Ogren, J. A.: Determining aerosol radiative properties using the TSI 3563 Integrating Nephelometer, Aerosol Sci. Tech., 29, 57-69, 1995.

Ångstrom, A.: On the atmospheric transmission of sun radiation and on dust in the air, Geogr. Ann., 11, 156-166, 1929.

Ansmann, A., Tesch, M, Seifert, P., Gro $\beta$, S., Freudenthaler, V., Apituley, A., Wilson, K. M., Serikov, I., Linne, H., Heinold, B., Hiebsch, A., Schnell, F., Schmidt, J., Mattis, I., Wandinger, U., and Wiegner, M.: Ash and fine-mode particle mass profiles from EARLINET-AERONET observations over central Europe after the eruptions of the Eyjafjallajökull volcano in 2010, J. Geophys. Res., 116, D00U02, doi:10.1029/2010JD015567, 2011.

Atkinson, D. B., Massoli, P., O’Neill, N. T., Quinn, P. K., Brooks, S. D., and Lefer, B.: Comparison of in situ and columnar aerosol spectral measurements during TexAQS-GoMACCS 2006: testing parameterizations for estimating aerosol fine mode properties, Atmos. Chem. Phys., 10, 51-61, doi:10.5194/acp-10-512010, 2010.

Atwood, S. A., Reid, J. S., Kreidenweis, S. M., Cliff, S. S., Zhao, Y., Lin, N.-H., Tsay, S.-C, Chu, Y.-C., and Westphal, D. L.: Size resolved measurements of springtime aerosol particles over the northern South China Sea, Atmos. Environ., 78, 134-143, 2013.

Bates, T. S., Anderson, T. L., Baynard, T., Bond, T., Boucher, O., Carmichael, G., Clarke, A., Erlick, C., Guo, H., Horowitz, L., Howell, S., Kulkarni, S., Maring, H., McComiskey, A., Middlebrook, A., Noone, K., O’Dowd, C. D., Ogren, J., Penner, J., Quinn, P. K., Ravishankara, A. R., Savoie, D. L., Schwartz, S. E., Shinozuka, Y., Tang, Y., Weber, R. J., and Wu, Y.: Aerosol direct radiative effects over the northwest Atlantic, northwest Pacific, and North Indian Oceans: estimates based on in-situ chemical 
and optical measurements and chemical transport modeling, Atmos. Chem. Phys., 6, 1657-1732, doi:10.5194/acp-6-1657-2006, 2006.

Bergstrom, R. W., Pilewskie, P., Russell, P. B., Redemann, J., Bond, T. C., Quinn, P. K., and Sierau, B.: Spectral absorption properties of atmospheric aerosols, Atmos. Chem. Phys., 7, 5937-5943, doi:10.5194/acp-7-5937-2007, 2007.

Bond, T. C., Anderson, T. A., and Campbell, D.: Calibration and intercomparison of filter-based measurement of visible light absorption by aerosols, Aerosol Sci. Tech., 30, 562-600, 1999.

Chen, Y.-C., Hamre, B., Frette, Ø, and Stamnes, J. J.: Climatology of aerosol optical properties in Northern Norway and Svalbard, Atmos. Meas. Tech. Discuss., 5, 7619-7640, doi:10.5194/amtd5-7619-2012, 2012.

Chin, M., Chu, A., Levy, R., Remer, L., Kaufman, Y., Holben, B., Eck, T., Ginoux, P., and Gao, Q. X.: Aerosol distribution in the Northern Hemisphere during ACE-Asia: Results from global model, satellite observations, and Sun photometer measurements, J. Geophys. Res.-Atmos., 109, D23S90, doi:10.1029/2004jd004829, 2004.

Cottle, P., Strawbridge, K., McKendry, I., O’Neill, N., and Saha, A.: A pervasive and persistent Asian dust event over North America during spring 2010: lidar and sunphotometer observations, Atmos. Chem. Phys., 13, 4515-4527, doi:10.5194/acp-13-45152013, 2013.

Dubovik, O. and King, M. D.: A flexible inversion algorithm for retrieval of aerosol optical properties from Sun and sky radiance measurements, J. Geophys. Res., 105, 20673-20696, doi:10.1029/2000JD900282, 2000.

Eck, T. F., Holben, B. N., Reid, J. S., Dubovik, O., Smirnov, A., O'Neill, N. T., Slutsker, I., and Kinne, S.: Wavelength dependence of the optical depth of biomass burning, urban, and desert dust aerosols, J. Geophys. Res., 104, 31333-31349, doi:10.1029/1999JD900923, 1999.

Eck, T. F., Holben, B. N., Dubovik, O., Smirnov, A., Goloub, P., Chen, H. B., Chatenet B., Gomes, L., Zhang, X.-Y., Tsay, S.C., Ji, Q., Giles, D., and Slutsker, I.: Columnar aerosol optical properties at AERONET sites in central eastern Asia and aerosol transport to the tropical mid-Pacific, J. Geophys. Res.Atmos., 110, D06202, doi:10.1029/2004JD005274, 2005.

Eck, T. F., Holben, B. N., Sinyuk, A., Pinker, R. T., Goloub, P., Chen, H., Chantenet, B., Li, Z., Singh, R. P., Tripathi, S. N., Reid, J. S., Giles, D. M., Dubovik, O., O’Neill, N. T., Smirnov, A., Wang, P., and Xia, X.: Climatological aspects of the optical properties of fine/coarse mode aerosol mixtures, J. Geophys. Res., 115, D19205, doi:10.1029/2010JD014002, 2010.

Eck, T. F., Holben, B. N., Reid, J. S., Giles, D. M., Rivas, M. A., Singh, R. P., Tripathi, S. N., Bruegge, C. J., Platnick, S., Arnold, G. T., Krotkov, N. A., Carn, S. A., Sinyuk, A., Dubovik, O., Arola, A., Schafer, J. S., Artaxo, P., Smirnov, A., Chen, H., and Goloub, P.: Fog- and cloud-induced aerosol modification observed by the Aerosol Robotic Network (AERONET), J. Geophys. Res., 117, D07206, doi:10.1029/2011JD016839, 2012.

Fitzgerald, J. W.: Marine aerosols: A review, Atmos. Environ. A., 25, 533-545, doi:10.1016/0960-1686(91)90050-H, 1991.

Hawkins, L. N., Russell, L. M., Covert, D. S., Quinn, P. K., and Bates, T. S.: Carboxylic acids, sulfates, and organosulfates in processed continental organic aerosol over the southeast Pacific
Ocean during VOCALS-REx 2008, J. Geophys. Res.-Atmos., 115, D13201, doi:10.1029/2009JD013276, 2010.

Kaufman, Y., Gitelson, A., Karnieli, A., Ganor, E., Fraser, R., Nakajima, T., Mattoo, S., and Holben, B. N.: Size distribution and scattering phase function of aerosol particles retrieved from sky brightness measurements, J. Geophys. Res., 99, 10341-10356, 1994.

O’Neill, N. T., Eck, T. F., Holben, B. N., Smirnov, A., Dubovik, O., and Royer, A.: Bimodal size distribution influences on the variation of Angstrom derivatives in spectral and optical depth space, J. Geophys. Res., 106, 9787-9806, doi:10.1029/2000JD900245, 2001a.

O’Neill, N. T., Dubovik, O., and Eck, T. F.: A modified Ångstrom exponent for the characterization of sub-micron aerosols, Appl. Optics, 40, 2368-2375, 2001b.

O’Neill, N. T., Eck, T. F., Smirnov, A., Holben, B. N., and Thulasiraman S.: Spectral discrimination of coarse and fine mode optical depth, J. Geophys. Res.-Atmos., 108, 4559, doi:10.1029/2002JD002975, 2003.

O’Neill, N. T., Eck, T. F., Reid, J. S., Smirnov, A., and Pancrati, O.: Coarse mode optical information retrievable using ultraviolet to short-wave infrared Sun photometry: Application to United Arab Emirates Unified Aerosol Experiment data, J. Geophys. Res.Atmos., 113, D05212, doi:10.1029/2007JD009052, 2008.

O’Neill, N. T., Perro, C., Saha, A., Lesin, G., Duck, T., Eloranta, E., Hoffman, M. L. Karumudi, A., Ritter, C., Bourassa, A., Aboud, I., Carn, S., and Savastiouk, V.: Impact of Sarychev sulphate aerosols over the Arctic, J. Geophys. Res.-Atmos., 117, D04203, doi:10.1029/2011JD016838, 2012.

PMEL: Atmospheric Chemistry Data Server, available at: http: //saga.pmel.noaa.gov/data/, last access: 5 November 2013.

Quinn, P. K. and Bates, T. S.: Regional aerosol properties: Comparisons of boundary layer measurements from ACE-1, ACE-2, Aerosols99, INDOEX, ACE-Asia, TARFOX, and NEAQS, J. Geophys. Res.-Atmos., 110, D14202, doi:10/1024/2004JD004755, 2005.

Quinn, P. K., Coffman, D. J., Bates, T. S., Welton, E. J., Covert, D. S., Miller, L., Johnson, J. E., Maria, S., Russell, L., Arimoto, R., Carrico, C. M., Rood, M. J., and Anderson, J.: Aerosol optical properties measured on board the Ronald H. Brown during ACE-Asia as a function of aerosol chemical composition and source region, J. Geophys. Res.-Atmos., 109, D19S01, doi:10.1029/2003JD004010, 2004.

Reid, E. A., Reid, J. S., Broumas, A. P., Cliff, S. S., Meir, M., Dunlap, M., Perry, K., and Cahill, T. A.: Characterization of African dust transported to Puerto Rico by individual particle and size segregated bulk analysis, J. Geophys. Res., 108, 8591, doi:10.1029/2002JD002935, 2003.

Reid, J. S., Hobbs, P. V., Ferek, Martins, J. V., Blake, D. R., Dunlap, M. R., and Liousse C.: Physical, chemical, and radiative characteristics of the smoke dominated regional hazes over Brazil, J. Geophys. Res., 103, 32059-32080, 1998.

Reid, J. S., Eck, T. F., Christopher, S. A., Hobbs, P. V., and Holben, B.: Use of the Angstrom exponent to estimate the variability of optical and physical properties of aging smoke particles in Brazil, J. Geophys. Res., 104, 27473-27489, doi:10.1029/1999JD900833, 1999.

Reid, J. S., Jonsson, H. H., Maring, H. B., Smirnov, A. A., Savoie, D. L., Cliff, S. S., Reid, E. A., Meier, M. M., Dubovik, O., and 
Tsay, S.-C.: Comparison of size and morphological measurements of coarse mode dust particles from Africa, J. Geophys. Res., 108, 8593, doi:10.1029/2002JD002485, 2003.

Reid, J. S., Brooks, B., Crahan, K. K., Hegg, D. A., Eck, T. F., O’Neill, N., de Leeuw, G., Reid, E. A., and Anderson, K. D.: Reconciliation of coarse mode sea-salt aerosol particle size measurements and parameterizations at a subtropical ocean receptor site, J. Geophys. Res.-Atmos., 111, D02202, doi:10.1029/2005JD006200, 2006.

Rissler, J., Vestin, A., Swietlicki, E., Fisch, G., Zhou, J., Artaxo, P., and Andreae, M. O.: Size distribution and hygroscopic properties of aerosol particles from dry-season biomass burning in Amazonia, Atmos. Chem. Phys., 6, 471-491, doi:10.5194/acp6-471-2006, 2006.

Saha, A., O’Neill, N. T., Eloranta, E., Stone, R. S., Eck, T. F., Zidane, S., Daou, D., Lupu, A., Lesins, G., Shiobara, M., and McArthur, L. J. B.: Pan-Arctic sunphotometry during the ARCTAS-A campaign, April 2008, Geophys. Res. Lett., 37, L05803, doi:10.1029/2009GL041375, 2010.
Salinas, S. V., Chew, B. N., Mohamad, M., Mahmud, M., and Liew, S. C.: First measurements of aerosol optical depth and Angstrom exponent number from AERONET's Kuching Site, Atmos. Environ., 8, 231-241, 2013.

Schuster, G. L., Dubovik, O., and Holben, B. N.: The Ångstrom Exponent and Bimodal Aerosol Size Distributions, J. Geophys. Res., 111, D07207, doi:10.1029/2005JD006328, 2005.

Smirnov, A., Holben, B. N., Kaufman, Y. J., Dubovik, O., Eck, T. F., Slutsker, I., Pietras, C., Rangasayi, and Halthore, N.: Optical properties of atmospheric aerosol in maritime environments, J. Atmos. Sci., 59, 501-523, doi:10.1175/15200469(2002)059<0501:OPOAAI>2.0.CO;2, 2002.

Tang, I. N.: Chemical and size effects of hygroscopic aerosols on light scattering coefficients, J. Geophys. Res., 101, 1924519250, 1996. 